\title{
POPULISMO Y SENTIDO CONTEMPORÁNEO DE LO POLÍTICO
}

PEDRO RIVAS 
SUMARIO

1. SOBRE LA CONCEPTUALIZACIÓN DEL POPULISMO. 1.1. UN ENFOQUE HISTÓRICO. 1.2. INTENTOS DE CARACTERIZACIÓN. 1.3. LOS RESTOS DEL CONCEPTO. 2. POPULISMO, DEMOCRACIA Y LIBERALISMO. 2.1. ESTADO DE LA CUESTIÓN. 2.2. POPULISMO Y SENTIDO CONTEMPORÁNEO DE LO POLÍTICO. 3. CONCLUSIONES. 


\title{
POPULISMO Y SENTIDO CONTEMPORÁNEO DE LO POLÍTICO ${ }^{1}$
}

\author{
PEDRO RIVAS ${ }^{2}$ \\ Profesor Titular de Filosofía del Derecho \\ Universidad Austral (Argentina)
}

En estos tiempos en que sobreabunda lo escrito, tratar una vez más uno de los asuntos académicos de moda puede parecer un intento de cansar a los lectores. En efecto, la literatura académica sobre populismo es abundante desde hace tiempo y ha crecido sin parar en fechas recientes. Parece inevitable preguntarse si es posible decir algo más y, sobre todo, que valga la pena. El autor de estas líneas piensa lógicamente que sí. Y es que, con todo, nadie duda que los actuales fenómenos populistas han generado esperanza en unos y preocupación en otros. Incluso entre quienes genera esperanza parece necesario tomarse en serio la preocupación ajena. En efecto, determinados regímenes políticos pasados que se caracterizaron por la violación masiva de los derechos humanos más básicos comenzaron con movimientos que guardan parecidos estrechos con lo que ahora identificamos como populismo. En el presente, la deriva de un régimen populista como el chavismo venezolano parece abonar esos temores. Y en Europa, el discurso contrario a la inmigración de algunos movimientos populistas hace crecer el miedo frente a ellos, en la medida en que desafían consensos básicos y fundamentales que parecían estar fuera de discusión ${ }^{3}$. En este punto, el populismo actual supone negar un estado de cosas que parecía inconmovible. De ahí que valga la pena hacer un esfuerzo por comprenderlo aunque se corra el riesgo de no hacer nada más que añadir papel al estado de la discusión.

1 Este trabajo forma parte de los resultados del proyecto de investigación «Coordinación y autoridad en el Estado Constitucional de Derecho. Desafíos teóricos y prácticos en un contexto de fragmentación moral» subvencionado por Agencia Nacional de Promoción Científica y Tecnológica del Ministerio de Ciencia, Tecnología e Innovación Productiva de la República Argentina (PICTO 20160095).

2 Facultad de Derecho. Universidad Austral. Sede Buenos Aires: Cerrito 1250, Ciudad de Buenos Aires, (C1010AAZ), Argentina. Email: pedro.rivas@udc.es

3 Tal vez porque el consenso era acerca de la necesidad de no discutir, otra cosa distinta es lo que los ciudadanos europeos pensaran realmente sobre el asunto. 
En este sentido, el propósito de este trabajo es doble. En primer lugar, vamos a afrontar el problema de la conceptualización del populismo. Para eso se sigue un doble acceso. Por un lado, se pretende mostrar la heterogeneidad de los populismos mediante una aproximación, a través de los estudios más canónicos, a sus principales manifestaciones históricas. Por otro lado, dicha heterogeneidad se manifiesta también en los intentos de caracterizarlo. A este respecto, la literatura académica es tan abundante y los rasgos que se le han dado son tan numerosos, que nos centraremos en algunos elementos fundamentales. En concreto, la cuestión de sus causas, su condición de fenómeno reactivo (o anti), la figura central del líder carismático populista y la comprensión del pueblo que subyace. Con esta doble vía de acceso al problema se pretende mostrar que el debate ha llegado a un callejón sin salida y se propone una manera operativa de evitarlo.

Las dificultades de su conceptualización dan la medida del segundo propósito de estas líneas. Y es que como parece inasible, se hace más perentorio comprender bien cómo el populismo presente desafía las democracias liberales contemporáneas. Este reto ha sido analizado de nuevo de manera abundante. Tras mostrar algunos ejemplos de los distintos niveles de análisis posibles, se presenta uno propio que intenta llegar al fondo de la cuestión: el populismo es ante todo un síntoma de las dificultades de nuestra comprensión de lo político, de esa que forma parte de nuestro imaginario y que hunde sus raíces en el pensamiento moderno.

\section{SOBRE LA CONCEPTUALIZACIÓN DEL POPULISMO}

En esta cuestión ya no es sólo un tópico decir que el populismo se resiste a ser definido sino incluso decir que es un tópico decir que es un tópico que el populismo se resiste a ser definido. Pareciera que no hay forma de dar con una definición ni siquiera con un conjunto de rasgos descriptivos que contemple todos los fenómenos populistas.

Las dificultades de conceptualizar el populismo han sido percibidas al menos desde hace medio siglo. Ya a fines de la década del 60 del pasado siglo, Mignone se preguntaba por la justificación del intento de conceptualización ante el temor de estar creando un campo incoherente de investigación. Además, señalaba la dificultad de hacerse cargo a la vez de discursos, ideas e instituciones a las que calificar de populistas. El riesgo era obtener un núcleo temático que no sirviera o tener que multiplicar los tipos de populismos hasta perder la unidad conceptual ${ }^{4}$. Y es que, como señalan MacKinnon y Petrone, el término sirve para referirse a realidades diferentes: movili-

${ }^{4}$ MIGNONE, K. (1970). «El populismo como movimiento político», en IONESCU, G. \& GELLNER, E. (comps.), Populismo. Sus significados y características nacionales, Buenos Aires, Amorrortu, pp. 241-244. Es traducción de L. Wolfson (1969) Populism. Its meanings and national characteristics, London, Weidenfeld and Nicolson. Se trata de una importante obra colectiva que sigue siendo completa en su aportación a una comprensión de los orígenes históricos del fenómeno populista. 
zaciones de diverso tipo, partidos, movimientos, ideologías, discursos, formas de gobierno, programas de gobierno, políticas públicas, etc. ${ }^{5}$. Además, resulta complejo conceptualizar una realidad como el populismo capaz de hacerse con agendas políticas contradictorias y objetivos propios de posiciones políticas contrapuestas. Por último, queda la cuestión de si considerar populistas a quienes reclaman el calificativo para sí mismos, o para quienes son calificados de esta manera por otros, incluso a pesar de rechazar la calificación ${ }^{6}$.

Al mismo tiempo, parece inevitable que el estudio del populismo requiera algún género de enfoque histórico. La cuestión es cómo hacerlo compatible con la necesidad de alcanzar un núcleo analítico que sea capaz de formular un conjunto de características empíricas. Como indica Panizza más recientemente, dar una relación de características es problemático. Por un lado, exige explicar las conexiones que se dan entre ellas y, en este sentido, priorizarlas y ordenarlas. Del mismo modo, requiere elegir entre una lista de máximos o de mínimos y decidir cuántas y cuáles forman el núcleo analítico del concepto ${ }^{7}$. Y con respecto a la explicación histórica, hay que señalar que también se hace necesaria la justificación del periodo elegido, es decir, explicar por qué quedan fuera tales o cuales fenómenos que de un modo u otro se han calificado se populistas ${ }^{8}$.

Vamos entonces a comprobar que tanto el enfoque histórico como el empírico no alcanzan a tematizar de modo convincente el fenómeno populista. En efecto, en primer lugar, un sencillo repaso por los fenómenos populistas que se han dado en la historia sirve para ver la heterogeneidad de los mismos, al punto que no resulta fácil hablar siquiera de una evolución del populismo.

\subsection{Un enfoque bistórico}

Según las explicaciones canónicas al uso, los dos primeros fenómenos populistas se produjeron de manera casi simultánea en el último tercio del siglo XIX. El populismo originario en los Estados Unidos de América es un movimiento que nace entre los agricultores comerciales contra los monopolios y la concentración de poder, los especuladores y los intermediarios del mercado?. Se desarrolla así una visión que exalta al agricultor y al trabajador honrado frente a los banqueros, los dueños del monopolio del ferrocarril y de la industria, protegidos estos últimos por privilegios

5 MACKINNON, M. M. \& PETRONE, M. A. (1998). «Introducción. Los complejos de la cenicienta», en MACKINNON, M. M. \& PETRONE, M. A. (comps.), Populismo y neopopulismo en América Latina. El problema de la cenicienta, Buenos Aires, Eudeba, pp. 11-12.

6 Ibidem, p. 14.

7 PANIZZA, F. (2009). «Introducción», en PANIZZA, F. (comp.), El populismo como espejo de la democracia, México, Fondo de Cultura Económica, p. 11.

8 Ibidem, p. 12.

9 HOFSTADTER, R. (1970). «Estados Unidos», en IONESCU, G. \& GELLNER, E. (comps.), ob. cit., pp. 16 y ss. 
políticos y de control de la moneda ${ }^{10}$. Este movimiento populista reclamaba una democracia real e igualitaria que evite la iniquidad de los aranceles, impuestos y política monetaria. Llegó a ser un partido político más, aunque al conseguir sustanciales mejoras en sus reclamaciones, terminó perdiendo fuerza. Con todo, dejó un legado de movilización popular, responsabilidad del gobierno por el bien común y necesidad de la vigilancia de los intereses creados $^{11}$.

De manera contemporánea al anterior, aparece el populismo ruso. Se trata de un movimiento más complejo impulsado por intelectuales, coincidente con el entrecruzarse de ideas ilustradas, eslavófilas, románticas, socialistas y revolucionarias, en la Rusia zarista de la época. El problema que se afronta es el principal del imperio ruso en el siglo XIX: la liberación del campesinado y la propiedad de la tierra ${ }^{12}$. Los orígenes del mismo en el plano de las ideas pueden remontarse al menos al impacto de la revolución de 1848 en algunos intelectuales ${ }^{13}$. En el plano de los hechos, ya en los años 30 y 40 del siglo XIX se afrontó el problema de la liberación de los siervos. Éstos tenían clara conciencia de que la tierra les pertenecía aunque ellos pertenecieran a sus señores. Por eso, la liberación debía acompañarse de la propiedad, cuestión resistida por la nobleza ${ }^{14}$. Finalmente la reforma comienza en 1857 con la entrega de la propiedad de la tierra a los siervos, previo pago de un precio o rescate, y termina con la liberación de estos en $1861^{15}$. Esta reforma es contemporánea a la aparición de grupos revolucionarios y de agitación junto con conspiradores políticos, donde surge desde 1863 la idea de que los intelectuales necesitan peregrinar hacia el pueblo para predicarle las nuevas ideas políticas y sociales, habida cuenta de la distancia percibida entre $\operatorname{ambos}^{16}$.

A partir de estos antecedentes se comienza a usar desde 1870 los términos populismo (narodnichestvo) y populista (narodnik) ${ }^{17}$. Las ideas fundamentales del populismo ruso serían la desconfianza ante toda democracia genérica, la creencia en un posible desarrollo autónomo del socialismo en Rusia, la fe en las futuras posibilidades de las comunidades campesinas (obshina) organizadas colectivamente en las aldeas, y la necesidad de crear tipos revolucionarios que rompan los lazos con el mundo circundante para dedicarse al pueblo y penetrar en él ${ }^{18}$. Estas ideas llevarían en 1874 a que se produjera una auténtica ida hacia el pueblo para vivir como él, compartir su miseria y aprender de él. Esta ida es percibida como un genuino deber y tiene como suje-

${ }^{10}$ Ibidem, pp. 26 y ss.

${ }^{11}$ Ibidem, pp. 35 y ss.

12 VENTURI, F. (1981). Los populistas rusos, Madrid, Alianza, capítulo I, passim. La bibliografía especializada reconoce en esta obra el estudio más completo publicado hasta el momento sobre el particular.

${ }^{13}$ Ibidem., p. 88.

${ }_{14}$ Ibidem., pp. 189 y ss.

${ }^{15}$ Ibidem., pp. 238 y ss.

${ }^{16}$ Ibidem., pp. 417 y ss.

${ }_{17}$ Ibidem., p. 89.

${ }^{18}$ Ibidem, p. 140. 
to a estudiantes e intelectuales. Se trató de un movimiento desorganizado, no centralizado y casi espontáneo, en el que los protagonistas confirmaron sus ideas colectivistas, de redistribución igualitaria y de un socialismo agrario ${ }^{19}$.

Ya en este punto hay quien ha mostrado que ambos movimientos que dan origen al término tienen apenas en común una o dos analogías sugestivas ${ }^{20}$. Y muy pronto se puede añadir a estos dos un tercer movimiento populista: el campesinismo de la Europa Oriental en el periodo entreguerras. En este caso se trata de una variante que posee un claro influjo de la difusión del populismo ruso decimonónico ${ }^{21}$. Ocurre en los nuevos estados nacionales del Este europeo que aparecen tras la Primera Guerra Mundial. Con la llegada del sufragio universal y la reforma agraria, con su consiguiente redistribución de la propiedad y emancipación de los campesinos, aparecen los partidos denominados precisamente agrarios y campesinos. Con una población rural masiva e incluso mayoritaria se entiende su aspiración a conquistar el poder político ${ }^{22}$. A pesar de las diferencias de intensidad y caracteres, estos populismos coinciden en tomar al campesino como prototipo social y tratar de modular sobre él la sociedad y el Estado. El liderazgo político campesino no es sólo producto de que estos son la mayoría de la nación, sino también de que sostienen los valores espirituales innatos de dicha comunidad política ${ }^{23}$.

Hasta este punto los distintos populismos parecían compartir una creencia en el carácter sacro de la tierra y de quienes la trabajan, junto con la fe en la pertenencia a una comunidad consensual llena de virtudes ${ }^{24}$. Frente a estos valores se encuentran los vicios urbanos y extranjeros de quienes buscan usurpar el poder. Igualmente, parecen movimientos apolíticos y antielitistas con ciertos rasgos idealistas y utópicos ${ }^{25}$.

En cambio, el populismo característico de Iberoamérica durante el siglo xx posee rasgos que muestran diferencias relevantes con la tradición populista mostrada hasta este momento. Al mismo tiempo, los diferentes movimientos populistas guardan también diferencias entre sí que han llevado a distinguir al menos entre populismos tempranos y clásicos. Los populismos tempranos son contemporáneos e incluso anteriores al populismo agrario de la Europa del Este en el periodo de entreguerras. Ocurren en las primeras décadas del siglo xx y agrupan a las emergentes clases medias urbanas liberales en busca de reformas democráticas ${ }^{26}$. En este ámbito las figuras de

\footnotetext{
19 Ibidem, 737 y ss.

20 MIGNONE, F., ob. cit., p. 241.

${ }^{21}$ IONESCU, G. (1970). «Europa Oriental», en IONESCU, G. \& GELLNER, E. (comps.), ob. cit., pp. 123 y ss.

22 Ibidem, pp. 132 y ss.

23 Ibidem, pp. 123 y ss.

24 MACRAE, D. (1970). «El populismo como ideología», en IONESCU, G. \& GELLNER, E. (comps.), ob. cit., p. 199.

25 Ibidem, pp. 199-201.

26 DRAKE, P. (1982). «Conclusion: Requiem for Populism?», en CONNIF, M. (ed.), Latin American Populism in comparative perspective, Alburquerque, University of New Mexico Press, pp. 237-239.
} 
Irigoyen y el partido Radical en Argentina serían paradigmáticas ${ }^{27}$. Sin embargo son los populistas clásicos quienes han sido objeto de una mayor atención en la medida en que han ocupado buena parte del espacio político ya desde la década del 30 hasta los años 70. Sus líderes (Haya de la Torre, Gaitán, Betancourt, Perón, Paz Estenssoro, Getulio Vargas, Velasco Ibarra) movilizaron bases más amplias con ciertas ideas socialistas. Sus objetivos pasaban por las mejoras sociales para los trabajadores, una reforma electoral para hacer real la democracia y la defensa de ideas nacionalistas frente a la intervención extranjera en la vida política de sus países. Se trata de movimientos fundamentalmente enraizados en las ciudades, asociados a procesos de industrialización, urbanización y diferenciación social. Sus promesas son en definitiva el bienestar social y el crecimiento económico ${ }^{28}$.

Como se ve, en este punto de la Historia resulta imposible encontrar un núcleo común. Si añadimos los populismos actuales la cuestión todavía se complica más. No vamos a entrar ahora en su análisis porque son todavía objeto de discusión y pertenecen a una categoría todavía viva y, en ese sentido, en desarrollo. Al mismo tiempo se trata de fenómenos conocidos por el lector y que forman parte en este momento del dominio público. Con todo, se hará referencia constante a los mismos en el siguiente epígrafe.

\subsection{Intentos de caracterización}

Las dificultades que muestra el enfoque histórico vuelven a hacerse presentes cuando se busca dar una comprensión temática del fenómeno populista. Vamos a comprobarlo acudiendo a las discusiones sobre algunas características reiteradas de los estudios al uso: las causas de su aparición, su carácter reactivo, la figura del líder carismático y la apelación al pueblo.

Por un lado, hay quienes ya desde los años 60 del pasado siglo han buscado el origen del populismo en los periodos de transición a la modernidad ocurridos en diversas sociedades contemporáneas ${ }^{29}$. Se trataría de un fenómeno en sociedades en desarrollo o si se prefiere de modernización ${ }^{30}$. En este sentido son paradigmáticas las tesis de Germani sobre el populismo latinoamericano. A su juicio, el populismo es una etapa histórica ligada a la modernización de los países latinoamericanos donde se produce la incorporación de masas previamente excluidas de la política. Esa moder-

27 MACKINNON, M. M. \& PETRONE, M. A. (1998), ob. cit., p. 15.

28 DRAKE, P. (1982), ob. cit., pp. 237-239.

29 LIPSET, S. M. (1960). Political Man. The Social Bases of Politics, Garden City, Doubleday, pp. 171-172.

30 STEWART, A. (1970). «Las raíces sociales», en IONESCU, G. \& GELLNER, E. (comps.), ob. cit., pp. 221-240. Un comentario detallado sobre dichas tesis en DE LA TORRE, C. (2013). «¿Es el populismo la forma constitutiva de la democracia en Latinoamérica?», en AIBAR GAETE, J. (coord.), Vox Populi. Populismo y democracia en Latinoamérica, Avellaneda, UNDAV Ediciones-UNGS-FLACSO México, p. 82. 
nización se caracteriza por unos procesos de industrialización ${ }^{31}$. Esta explicación encontró críticas ya en el momento de ser formulada ${ }^{32}$. A pesar de tales críticas hay quien ha seguido insistiendo en que el populismo se produce en sistemas débilmente institucionalizados ${ }^{33}$. Y quien sostiene todavía que el populismo es una forma de resistencia a proyectos de modernización ${ }^{34}$. Con todo, la aparición de fenómenos populistas en sociedades como las europeas, plenamente modernizadas y con alto grado de institucionalización, termina por producir el abandono de dichas tesis. En efecto, ya no estamos ante masas de campesinos o de obreros, el pueblo no está excluido de la educación y los gobiernos aparecen legitimados por mayorías populares en elecciones libres ${ }^{35}$.

Por lo anterior, no puede extrañar que algunos hayan optado por una causa menos determinada del origen de los fenómenos populistas y se haya preferido hablar simplemente de crisis como condición de emergencia ${ }^{36}$ o circunstancia que aumenta la probabilidad $^{37}$. La dificultad en ponerse de acuerdo sobre qué es una crisis, cuáles son sus rasgos, qué tipos existen, etc., hace que esta referencia resulte pobre y explique poco o nada. Lo mismo ocurre con la mención que hace Laclau a las demandas insatisfechas por el sistema para explicar qué pone en marcha un movimiento populista ${ }^{38}$.

Cuando se intenta concretar más, se corre el riesgo de nuevo de dejar inexplicados algunos fenómenos populistas. Por ejemplo, es el caso de quien comprende el populismo como resultado de la conciencia colectiva de una situación desventajosa en lo que respecta a la riqueza ${ }^{39}$. En este caso, el populismo ruso quedaría inexplicado porque no tuvo detrás ninguna conciencia colectiva. También algunos populismos actuales europeos quedarían fuera de la explicación ya que no se focalizan en denunciar desigualdades económicas. Otros intentos de una mayor concreción señalan que en el origen del populismo habría un resentimiento contra el orden impuesto a la sociedad por una clase gobernante que goza del monopolio del poder, la propiedad, la educación y la cultura ${ }^{40}$. En este caso el uso del término resentimiento contiene un juicio moral negativo que es descalificatorio sin justificación: es más, si es cierto tal mono-

31 GERMANI, G. (1966). Política y sociedad en una época de transición, Buenos Aires, Paidós, pp. 208216, especialmente en p. 210.

32 DE LA TORRE, C. (2008). «Populismo, ciudadanía y Estado de Derecho», en DE LA TORRE, C. \& PERUZZOTTI, E. (eds.), El retorno del pueblo. Populismo y nuevas democracias en América Latina, Quito, FLACSO Ecuador/Ministerio de Cultura, pp. 24-27.

33 WEYLAND, K. (2003). «Neopopulism and Neoliberalism in Latin America: how much affinity?». Third World Quarterly, vol. 24, num. 6, pp. 1097-1098.

${ }^{34}$ DE LA TORRE, C. (2013), ob. cit., pp. 82-84.

35 CANOVAN, M. (2005). The People, Cambridge, Polity Press, pp. 80-81.

36 MACKINNON, M. M. \& PETRONE, M. A. (1998), ob. cit., p. 44.

37 PANIZZA, F. (2009), ob. cit., p. 24.

38 LACLAU, E. (2009), «Populismo: ¿qué nos dice el nombre?», en PANIZZA, F. (2009), ob. cit., pp. 53-58.

39 MIGNONE, K. (1970), ob. cit., p. 255.

40 SHILS, E. (1956). The torment of secrecy: the background and consequences of American security, Glencoe (Ill.), Free Press, pp. 100-101. 
polio lo que se llama resentimiento no sería sino sentido de la justicia. Además, de nuevo en los populismos europeos presentes no parece que se denuncie que la clase gobernante monopolice la educación y la cultura, ni siquiera la propiedad.

Los problemas para dar con un origen común a los fenómenos populistas se repiten al intentar señalar otros caracteres. Por ejemplo, es habitual entre quienes los han estudiado señalar el carácter negativo, es decir, su condición de movimientos que se definen por estar en contra de. Desde lo más general a lo más particular, podemos comenzar con quien señala el carácter anti-institucional del populismo ${ }^{41}$. El problema de esta tesis es, como se ha dicho con agudeza, que en realidad los fenómenos populistas quieren reinstitucionalizar un orden político y no simplemente destruir el existente ${ }^{42}$.

También inciden en el carácter anti quienes califican el populismo de antiestablishment o de anti-statu quo. De entre los primeros encontramos de nuevo a Laclau, junto con Canovan ${ }^{43}$, Roberts $^{44}$ y Barr ${ }^{45}$. Por una parte, el propio Barr admite la poca capacidad para definir al populismo de una característica como la mencionada, que puede también encontrarse en fenómenos no populistas ${ }^{46}$. Por otro lado, hay que tener presente que si no definimos qué entendemos por establishment corremos el riesgo de identificar populismo con la simple y llana oposición política, en la medida en que ésta es por definición contraria al establishment gobernante en alguna medida. La referencia al populismo como discurso anti-statu quo ${ }^{47}$ o como opción que desafía al statu quo ${ }^{48}$ adolece exactamente de los mismos problemas que acabamos de mencionar: se da también en fenómenos no populistas al punto que cualquier oposición política podría calificarse en cierta medida de contraria al statu quo.

Por lo demás, cuando se concreta el carácter anti, también quedan al margen numerosos fenómenos populistas. Así, la caracterización del populismo como anti-intelectual y anti-extranjeros ${ }^{49}$ excluye populismos europeos presentes generados y encabezados por intelectuales (o sedicentes intelectuales) que además defienden políticas migratorias no restrictivas. Al margen de que el populismo ruso decimonónico era precisamente un movimiento de intelectuales, producto en buena medida de reflexiones, discusiones y debates entre intelectuales.

41 LACLAU, E. (2005). La razón populista, Buenos Aires, Fondo de Cultura Económica, pp. 107-108.

42 PANIZZA, F. (2008). «Fisuras entre populismo y democracia en América Latina», en DE LA TORRE, C. \& PERUZZOTTI, E. (eds.), ob. cit., p. 84.

43 CANOVAN, M. (2005), ob. cit., p. 89.

44 ROBERTS, K. M. (2008). «El resurgimiento del populismo latinoamericano», en DE LA TORRE, C. \& PERUZZOTTI, E. (eds.), ob. cit., p. 57.

45 BARR, R. R. (2009). «Populists, outsiders and anti-establishment politics», Party Politics, vol. 15, num. 1, pp. 31-33.

46 Ibidem.

47 PANIZZA, F. (2009), ob. cit., p. 13.

48 SAENZ DE TEJADA, R. (2013), «Populismo y crítica a la democracia», en AIBAR GAETE, J. (coord.), ob.cit., pp. 285-313.

49 WILES, P. (1970). «Un síndrome, no una doctrina: algunas tesis elementales sobre el populismo», en IONESCU, G. \& GELLNER, E. (comps.), ob. cit., p. 203. 
Pero, al margen de esta característica, hay que detenerse en el rasgo que aparece de manera casi unánime en todas las caracterizaciones del fenómeno populista: la necesidad de una figura carismática que ejerce el liderazgo de cada movimiento populista en cuestión. En este punto, los estudiosos del populismo iberoamericano se llevan la palma aunque, como veremos, no están solos.

Al margen del ámbito iberoamericano, ya en los años 50 del siglo pasado Shils señalaba como uno de los principios del populismo la relación directa del pueblo con el líder, sin necesidad de mediación institucional alguna ${ }^{50}$. También Wiles en la década del 60 incluía en su caracterización del populismo el contacto místico del líder con las masas ${ }^{51}$. Y mucho más recientemente Barr insiste en que la organización propia de los movimientos populistas consiste en la carencia de autonomía en su interior, es decir, en la relación vertical de las masas con su líder al que siempre le son obedientes $^{52}$.

Con todo, como ya se ha señalado, son los estudios sobre el populismo iberoamericano los que se detienen a describir la importancia y el papel del líder populista. De nuevo, puede comenzarse por mencionar el análisis clásico de Germani para quien el populismo latinoamericano requiere de una masa disponible y en estado de anomia, es decir necesitada de un líder carismático ${ }^{53}$. De la Torre ha insistido, por su parte, en la importancia de explicar el poder convocante del líder populista sin acudir para ello a la supuesta capacidad manipuladora del mismo o a la irracionalidad de las masas $^{54}$. Igualmente Roxborough caracteriza al populismo como un fenómeno que se da en masas amorfas vinculadas a un líder carismático ${ }^{55}$.

De la misma forma en los últimos años ha permanecido constante la referencia al líder carismático entre los estudiosos del populismo. Para unos, porque la movilización política típica del populismo es de arriba hacia abajo, es decir a partir de líderes personalistas $^{56}$, al punto que tal movilización crea y define un pueblo y un líder ${ }^{57}$. Otros inciden en la centralidad de la figura del líder a la hora de configurar las masas populistas $^{58}$, o en la construcción de los valores del pueblo que se encarnarían precisamente en el propio líder ${ }^{59}$. Incluso quienes finalmente reconocen que no es un elemento necesario del populismo, no pueden sustraerse a la tentación de dedicar

50 SHILS, E. (1956), ob. cit., pp. 102-103

51 WILES, P. (1970), ob. cit., p. 203.

52 BARR, R. R. (2009), ob. cit., p. 42.

53 GERMANI, G. (1966), ob. cit., p. 214.

54 DE LA TORRE, C. (1992). «The Ambigous Meanings of Latin American Populisms», Social Research, vol. 59, num. 2, pp. 408-410.

55 ROXBOROUGH, I. (1984). «Unity and Diversity in Latin American History», Journal of Latin American Studies, vol. 16, num. 1, pp. 9-11.

56 ROBERTS, K. M. (2008), ob. cit., p. 58.

57 CASULLO, M.E. (2014/2015). «¿En el nombre del pueblo? Por qué estudiar el populismo hoy», Post Data, vol. 19, núm. 2, p. 284.

58 PANIZZA, F. (2008), ob. cit., p. 91.

59 DE LA TORRE, C. (2013), ob. cit. p. 83. 
bastante espacio a su caracterización: el líder se relaciona directamente con las masas y logra que éstas se identifiquen con él de modo instintivo, espontáneo e irracional, porque ven en él el símbolo de la identidad del pueblo, alguien al mismo tiempo extraordinario y situado fuera de lo político ${ }^{60}$.

En realidad, el hecho de que algunos fenómenos populistas hayan sobrevivido al liderazgo fundacional relativiza lo anterior. Pero, de nuevo, los populismos europeos de fines del siglo xx y principios del actual ponen en crisis esta caracterización del populismo como movimiento político necesitado de liderazgo carismático fuerte. Al contrario, algunos son claramente asamblearios y prácticamente todos están sobreviviendo al recambio de sus principales referentes políticos. Al punto que algunos se presentan con un funcionamiento interno más democrático que el de los demás partidos políticos. Nada pareciera distinguir hoy a la dirigencia política de los partidos populistas de los no populistas.

El contrapunto al tratamiento del líder populista es el de la categoría del pueblo, que está en la entraña misma del propio término populismo. Constituye un lugar común la afirmación de que el populismo crea un sujeto popular, pero de forma que transforma la diferencia en ruptura antagónica entre dos bloques irreconciliables. Por decirlo más claramente, el populismo construye un enemigo ${ }^{61}$. El pueblo sería el sujeto fundante y el destino último de la nación ${ }^{62}$. El núcleo analítico del populismo estaría en la constitución del pueblo como actor político. El pueblo es una construcción política cuyo modo de identificación es el antagonismo: establecer quién es el enemigo del pueblo supone definir quién es el pueblo ${ }^{63}$. En el populismo, el pueblo está formado por los que se consideran privados del derecho de representación y excluidos de la vida política ${ }^{64}$. Esos excluidos no son necesariamente una clase social ni se incorporan al movimiento como clase ${ }^{65}$. Se produce una nueva representación de la comunidad legítima en la que una parte, que ha venido siendo víctima, se apropia del todo. La parte relegada no se presenta como una entre otras sino que, en nombre del daño recibido, reclama la representación plena de la comunidad política ${ }^{66}$. El populismo tiene así una concepción monolítica, holística, del pueblo. Lo asume como si fuera una unidad sin diferencias internas ni desacuerdos ${ }^{67}$. Frente al principio de

60 PANIZZA, F. (2009), ob. cit., pp. 34-40.

61 LACLAU, E. (2005), ob. cit., p. 110.

62 AIBAR GAETE, J. (2008). «Sobre alquimistas e imaginadores. Populismo y nación», en DE LA TORRE, C. \& PERUZZOTTI, E. (eds.), ob. cit., p. 178.

${ }^{63}$ PANIZZA, F. (2009), ob. cit., p. 13.

64 Ibidem, p. 33.

65 ROXBOROUGH, I. (1984), ob, cit., p. 25.

66 BARROS, S. (2013). «Despejando la espesura. La distinción entre identificaciones populares y articulaciones políticas populistas», en ABOY CARLES, G., BARROS, S. Y MELO, J., Las brechas del pueblo. Reflexiones sobre identidades populares y populismo, Los Polvorines (Buenos Aires), UNGS-UNDAV Ediciones, pp. 55-60.

67 WOLKENSTEIN, F. (2015). «What can we hold against populism?», Philosophy and Social Criticism, vol. 41, num. 2, p. 111. 
representación liberal, el populismo defiende la participación directa ${ }^{68}$, de ahí su querencia plebiscitaria ${ }^{69}$. Por lo anterior, se entiende que se afirme que el populismo no es democrático ni antidemocrático ${ }^{70}$, pues aunque existan experiencias populistas antidemocráticas todo depende de con qué otros discursos se articule para resultar o no compatible con la democracia ${ }^{71}$. En este punto, se muestra la capacidad del populismo para hacerse con agendas políticas contrapuestas, lo que volvería a revelar su carácter ambiguo ${ }^{72}$. Con todo, ambigüedad no es exactamente lo mismo que indefinición ideológica. En efecto, que pueda ser empleado por ideologías contrapuestas no significa que los populismos sean indefinidos. Al contrario, algunos de ellos pretenden defender algunas ideas políticas claras, comprensibles para cualquiera y que les distingue fuertemente del resto de las opciones políticas. A mayores, en el momento presente los partidos políticos se caracterizan cada vez más por su indefinición y por parecerse unos a otros, al punto que necesitan resaltar como dramáticas las pequeñas diferencias entre ellos o vender sobre todo su capacidad de gestión pública o la corrupción del bando contrario.

A mi juicio, y con todos los matices, la apelación al pueblo es un rasgo que todavía puede encontrarse todavía de alguna forma en los populismos europeos presentes. Lógicamente se da con un tono diferente al de los populismos iberoamericanos clásicos, propios del siglo Xx. No se presenta ahora al pueblo como privado de representación ni excluido de la vida política. O mejor dicho, se le presenta como mal representado hasta que la aparición del movimiento populista daría voz a quienes no encontraban un partido con el que identificarse. De una forma o de otra, el populismo trata de dar voz a los sin voz que se sienten ajenos a los consensos políticos y económicos, y se consideran excluidos o incluso maltratados por los medios de comunicación convencionales. Con todo es fácil observar que este rasgo es común con otros fenómenos políticos y sociales a los que no denominamos populistas. Tampoco parece que los populismos europeos reclamen la representación plena de la comunidad política o que asuman una concepción holística del pueblo, en la medida siquiera en que los resultados electorales les muestran su verdadero alcance que se reduce a una porción habitualmente menor del electorado. En este caso, encontramos otros movimientos sociales que no son comúnmente calificados como populistas y que, sin embargo, sí que pretenden la representación plena de determinados sectores de la población. Por ejemplo, el feminismo y el indigenismo pretenden hablar por las mujeres y por una determinada etnia in toto. Igualmente habría que matizar el carácter antagónico de los populismos europeos en la medida en que la retórica de la ruptura y de la cons-

${ }^{68}$ MACKINNON, M. M. \& PETRONE, M. A. (1998), ob. cit., pp. 44-45. También WORSLEY, P. (1970). «El concepto de populismo», en IONESCU, G. \& GELLNER, E. (comps.), ob. cit., p. 301.

${ }^{69}$ BARR, R. R. (2009), ob. cit., p. 38.

70 WORSLEY, P. (1970), ob. cit., pp. 302-303.

71 PANIZZA, F. (2008), ob. cit., p. 80.

72 MACKINNON, M. M. \& PETRONE, M. A. (1998), ob. cit., p. 14. 
trucción del enemigo se da en ocasiones en partidos y movimientos no populistas. Es más, curiosamente en ocasiones la reacción que provoca un movimiento populista en sus adversarios consiste precisamente en que éstos tratan al populismo como un enemigo que debe ser excluido del debate público y cuyas ideas no deben ser siquiera discutidas ${ }^{73}$. De la misma forma, el carácter de víctima que una parte de la comunidad reclamaría para erigirse en representación del todo, puede encontrarse en movimientos no populistas. En efecto, todo grupo social que siente haber sufrido discriminación (sea real o no) pretende por el mismo hecho gozar de una autoridad especial para decidir sobre políticas generales. Y, a mayores, es práctica común de cualquier partido la pretensión de asumir la representación de cualquier colectivo que se pretenda víctima (de nuevo, real o no) para ubicar al partido contrario en la posición de victimario, es decir de enemigo ${ }^{74}$. Todo lo anterior pareciera indicar que el problema del populismo es de grado. Y al entrar en el grado nos abocamos a la indefinición una vez más. Porque dependerá de las sensibilidades fijar los límites. Y esa sensibilidad puede como mucho llegar a tener rasgos comunes solamente entre quienes pertenecen a una misma comunidad política.

\subsection{Los restos del concepto}

Las dificultades expuestas tienen su origen en algo que salta a la vista y que, sin embargo, apenas parece advertirse en los estudiosos del populismo. Durán Migliardi advierte en fecha reciente que los nuevos acontecimientos dejan anticuada cualquier definición $^{75}$. En efecto, por un lado el problema para definirlo radica en que la realidad te va desmintiendo cualquier definición. Como hemos visto, les ocurrió en primer lugar a los que lo catalogaron de fenómeno de sociedades rurales y agrarias. Luego, quienes se focalizaron en los populismos iberoamericanos y teorizaron sobre la figura del líder y su relación con las masas. Y llegados a este punto no me resisto a mencionar un último ejemplo muy reciente que puede servir de corolario a lo que se viene sosteniendo. En un ensayo, por lo demás valioso, publicado en 2015 (aunque por lo que se verá fue escrito un poco antes de esa fecha), se afirma que allí donde la defensa del arraigo ha sido reconocida e integrada en el debate público, no se dan fenómenos populistas. Y se invoca los ejemplos de Gran Bretaña y España ${ }^{76}$. Los recientes acontecimientos del referendum por el que el Reino Unido abandonó la Unión Europea y la aparición de Podemos en la escena política española desmienten dicha afirmación

${ }^{73}$ Lo hacen notar CANOVAN, M. (2005), ob. cit., p. 83 y DELSOL, CH. (2015). Populismos. Una defensa de lo indefendible, Buenos Aires, Ariel, pp. 57-58.

${ }^{74}$ Me he ocupado de la cuestión en Salir de la oscuridad. Perdón, Derecho y Política en los procesos de justicia transicional, Cizur Menor, Aranzadi (Thomson Reuters), 2013.

75 DURÁN MIGLIARDI, C. (2013), «Neopopulismo: la imposibilidad del nombre», en AIBAR GAETE, J. (coord.), ob. cit., pp. 92-93.

76 DELSOL, CH. (2015), ob. cit., p. 177. 
apenas acaba de formularse. En el fondo es el destino de quien trata de hacer ciencia de la libertad humana y el inevitable retraso con que dicha ciencia sobre las acciones humanas libres llega a su comprensión. No hay forma de pronosticar o, si se prefiere, se puede pronosticar confiando en que tarde o temprano algún fenómeno humano coincidirá con el pronóstico.

Frente a lo anterior, podría pensarse en la posibilidad de expulsar determinados fenómenos políticos y sociales del concepto de populismo. Parece algo de todo punto imposible. Precisamente en esta imposibilidad radica, a mi juicio, la dificultad actual para definirlo: en que es un término de uso común, especialmente en boca de políticos, comunicadores y los llamados creadores de opinión. De ahí que primero se cataloga a algún movimiento o partido político de populista, se instala fuertemente en el uso común y termina por darse por válido, sin importar si la calificación es correcta, si aclara o si confunde. Además, como se mencionó, el calificativo se emplea corrientemente con un marcado matiz peyorativo. Considero que puede traerse a colación otros ejemplos similares de cómo el uso habitual confunde un concepto e incluso lo echa a perder.

En primer lugar, podemos comprobar lo ocurrido con el término «tolerancia». En el caso de la tolerancia, llama la atención cómo perdió su sentido secular que la asignaba a realidades negativas que, precisamente por eso, sólo se podían tolerar. Aún más, se indicaba normalmente que las cosas se toleraban mejor o peor, precisamente porque dependía de cada sujeto y de la realidad concreta a tolerar. Cuando se extiende su uso y se hace desaparecer cuál es el objeto que se tolera o no se tolera y de qué modo se tolera, entonces se emplea para referirse a realidades que no son negativas (tolerar a los inmigrantes, tolerar otros modos de pensar, tolerar otras culturas, etc.) o queda reducido en su antónimo («intolerante») a una simple descalificación. Aún más, se convierte en una descalificación tan rotunda que no parece admitir réplica o, si se prefiere, que requiere una réplica lo suficientemente compleja como para no poder paliar el efecto negativo de haber recibido el calificativo de «intolerante». Tal vez por eso se convirtió en un arma arrojadiza de la lucha política que debía ser lanzada antes de poder recibir su impacto. Como prueba de lo anterior, sirve también llamar la atención acerca del modo de usar el término. Y es que resulta tan ominoso ser calificado de intolerante que ante lo intolerable sólo cabe la «tolerancia cero». Es decir que no es posible un sentido positivo de «intolerancia» y por eso se acude a expresiones como «tolerancia cero».

Una vez agotado el término tolerancia, ha comenzado a ocurrir un fenómeno similar con el empleo como sufijo del término «fobia». O bien con el uso del calificativo con el sufijo «-fobo». En este caso con el añadido de que una fobia se asocia habitualmente con un tipo de problema o incluso de una enfermedad mental (por ejemplo, la agorafobia). De nuevo estamos ante una descalificación que, como la de intolerante, resulta tan fuerte que no deja lugar a la réplica. Consiguientemente deja de tener importancia en qué ámbito se emplea o qué conducta se pretende juzgar como tal y si realmente se podía calificar así. 
Algo parecido habría ocurrido con el término «fundamentalismo». Por una parte, porque «fundamentalismo» se ha convertido en una palabra que sirve para casi todo. Basta con añadirle un calificativo posterior, con independencia, al parecer, de que se le pueda añadir también el calificativo contrario ${ }^{77}$. De ahí que corramos el riesgo de no saber de qué estamos hablando. En efecto, cuando un término empieza a servir para una cosa y para su contraria corre el riesgo de no servir para nada. Por otro lado, se usa sobre todo para descalificar a priori la postura que se quiere criticar, porque permite colocarse cómodamente en un plano positivo frente al contrario «fundamentalista» ${ }^{78}$. De esta forma se repite lo que acaba de mencionarse con el ejemplo de la «tolerancia»: interesa emplearlo en el propio favor (es decir, en demérito del contrario) antes de que se emplee en contra de uno. Y así da lo mismo de qué se esté discutiendo y cuál sea la racionalidad de los argumentos, porque ante todo se trata de un recurso retórico que no pretende significar nada en concreto. A mi juicio, cuando una palabra entra en el ámbito de la retórica político-mediática tiene muchas posibilidades de quedar inservible.

Por todo lo anterior, ya se ve que es una tarea inútil la de dar un conjunto de criterios positivos del populismo que permanezca igual y que resista todos los ejemplos contrarios que se pueden encontrar. En el fondo, no nos queda más salida que definir como populismo a todo movimiento político que se identifica a sí mismo y/o que es identificado por otros con ese calificativo. E intentar escapar al componente retórico del término por el sencillo hecho de tomarse en serio cada uno de ellos. Tomarse en serio los populismos presentes es precisamente considerar su desafío a las democracias liberales actuales.

\section{POPULISMO, DEMOCRACIA Y LIBERALISMO}

\subsection{Estado de la cuestión}

La relación entre populismo, democracia y liberalismo parece ser vista comúnmente como contradictoria. En ese sentido hay quienes arriesgan una metáfora para expresar dicha relación. Así, para unos es una patología de la democracia porque el populismo sostiene la ficción de la voluntad popular como voluntad homogénea ${ }^{79}$. Otros califican al populismo de fantasma de la democracia liberal porque sirve preci-

${ }_{77}$ Basta echar mano de cualquier buscador de internet y hacer la prueba para encontrar un volumen enorme de resultados.

78 Pueden verse algunos ejemplos en las referencias de otros trabajos que hacen por ejemplo DONCEL DOMÍNGUEZ, J. A. (1999). "Sobre integrismos y fundamentalismo. Análisis y conceptualización», El Basilisco, vol. 25, pp. 31-40, y OLLERO, A. (1995). "Tolerancia y verdad», Scripta Theologica, vol. 27, pp. 885-920.

79 ABTS, K. \& RUMMENS, S. (2007). «Populism versus Democracy», Political Studies, vol. 55, num. 2, p. 414 
samente para conocer los miedos de ésta ${ }^{80}$. Para otros se trata de la sombra de la democracia porque le sigue siempre y es oscura ${ }^{81}$. En otras palabras, se trataría del reverso de la democracia, una amenaza a la que está expuesta cuando los conflictos están tan exacerbados que no parecen resolverse en la esfera política y una sensación de fragmentación social invade la sociedad entera ${ }^{82}$. Y también hay quien la denomina espejo de la democracia porque muestra sus defectos e imperfecciones, en concreto, los puntos ciegos del liberalismo político y las dificultades del principio de representación ${ }^{83}$.

A partir de aquí los niveles de análisis de la relación varían, aunque partiendo habitualmente de que se trata de una relación problemática. Por ejemplo, caben visiones desde lo más inmediato que sostienen que la democracia liberal convivirá siempre con el populismo porque la globalización capitalista y su consiguiente financiarización de la Economía y aumento de la desigualdad producirán cambios en la estructura social y desacoples de la representación política. El populismo sería una respuesta a mano ante estos problemas ${ }^{84}$. O bien porque la democracia liberal genera periferización de la fuerza laboral, es decir, una separación entre clases trabajadoras industriales y élite educada y cosmopolita, junto con distribución desigual del ingreso, disminución del crecimiento económico y mayor diversidad social ${ }^{85}$.

Es posible también centrar la mirada en el principio de representación como lugar de contradicción entre populismo y democracia liberal. Así, para unos el populismo aparece cuando el representante ya no actúa por otros, es decir bajo su autorización, sino en lugar de otros porque ya son uno y lo mismo el representante y sus represen$\operatorname{tados}^{86}$. Para otros, la diferencia entre el populismo y la encarnación moderna de los ideales democráticos, es decir la poliarquía liberal, es propiamente la distinta interpretación del principio de representación. En el caso del populismo se funda en los presupuestos de la equivalencia, similitud y proximidad entre representante y representados. A los ojos del populismo la representación liberal, con su mediación entre pueblo y poder, puede introducir solamente distorsiones y deformaciones de la voluntad popular ${ }^{87}$.

En una perspectiva diferente, se afirma que el populismo es algo interno a la democracia. En efecto, los elementos populistas de defensa de la soberanía popular frente a las élites directivas corruptas parecen salvar la distancia entre los ideales

80 DURÁN MigLIARDI, C. (2013), ob. cit., p. 136.

81 CANOVAN, M. (1999). «Trust the People! Populism and the Two Faces of Democracy», Political Studies, vol. 47, num. 1, p. 10.

82 ARDITI, B. (2010). La política en los bordes del liberalismo: diferencia, populismo, revolución, Barcelona, Gedisa, pp. 152-153.

83 PANIZZA, F. (2009), ob. cit., pp. 47-49.

${ }^{84}$ CASUlLO, M.E. (2014/2015), ob. cit., p. 292.

85 PÉREZ-LIÑÁN, A. (2017). « Podrá la democracia sobrevivir al siglo XXI?», Nueva Sociedad, vol. 267 , p. 39.

86 ARDITI, B. (2010), ob. cit., p. 154.

${ }^{87}$ AMATO, T. (2010). «Populismo e democrazia», L'Acropoli, vol. XI, num. 4, pp. 413 y ss. 
democráticos y las democracias realmente existentes. De ahí que se corra siempre el riesgo de la aparición del populismo con su carácter redentor y repolitizador de los problemas que dichas élites no resuelven ${ }^{88}$. De alguna manera, el populismo vendría entonces a dar respuesta a dos dilemas que, según Dahl, caracterizan nuestras democracias: quién constituye un pueblo para el propósito de un gobierno democrático y cómo se concilia la soberanía popular con el constitucionalismo ${ }^{89}$.

En un nivel más profundo, hay quienes ven el debate sobre el populismo como parte de un problema mayor: el de la comprensión de la democracia. En último término, el populismo nos remitiría a la visión de la democracia que sostiene Carl Schmitt. Para éste, la democracia supone identidad no mediada entre gobernantes y gobernados. Por eso, democracia y representación son alternativas. La medicación parlamentaria es un elemento no democrático y el gobierno representativo no logra crear un principio de unidad política. Por eso, el populismo, como ocurre con Schmitt, supone la oposición drástica entre democracia y liberalismo ${ }^{90}$.

Frente a lo anterior cabe aceptar que el populismo es producto de las deficiencias de la democracia representativa y defender que la versión deliberativa de la democracia supera esas deficiencias. En efecto, el populismo procedería de las promesas frustradas de la democracia en el terreno de la igualdad con la consiguiente imposibilidad de desarrollo de la autonomía personal. Sin embargo, la democracia deliberativa se coloca por encima del populismo gracias a que alcanza mejor el criterio normativo de la democracia, una relación simétrica entre ciudadanos libres e iguales. Y es que la democracia deliberativa pretende instaurar procedimientos de intercambio reglado entre ciudadanos sobre la base de razones generales que involucran el interés común de todos los afectados ${ }^{91}$. Sin entrar a valorar estas distinciones, hay quien defiende en oposición que el populismo muestra que la percepción liberal (y esto incluye la deliberativa) de lo político es simplemente errada. En efecto, el liberalismo sostiene que la discusión política debe regularse por la razón pública, es decir, por aquella que habla el lenguaje del bien común y no de intereses de grupo. La realidad nos muestra que los participantes en lo político expresan más bien identidades colectivas, divisiones sociales e intereses distintos. Tales identidades, divisiones e intereses son el motor de la participación política y el contenido propio de la política misma. La tendencia liberal de separar lo político de sus conflictos constitutivos es antipolítica y abre la puerta al populismo como movilizador de esas identidades colectivas ${ }^{92}$.

En cambio, hay quien rechaza que el populismo y la democracia liberal sean antitéticos. La tentación populista es simplificar la democracia moderna y olvidar los

88 ROVIRA KALTWASSER, C. (2014), ob. cit., p. 484.

89 Ibidem, pp. 472-476.

90 PERUZZOTTI, E. (2008). «Populismo y representación democrática», DE LA TORRE, C. \& PERUZZOTTI, E. (eds.), ob. cit., pp. 97-102.

91 GUARIGLIA, O. (2011). «La Democracia en América Latina: la alternativa entre populismo y democracia deliberativa», Isegoría, vol. 44, pp. 66-67.

92 WOLKENSTEIN, F. (2015), ob. cit., pp. 115-116. 
límites del ejercicio del poder y la protección de las minorías. La tentación de sus críticos es aceptar que la democracia liberal moderna es el cruce de dos aspectos irreconciliables: el principio democrático y el constitucionalismo liberal, es decir, a un lado el pueblo y al otro las libertades y los derechos. La mayor parte de su historia, el liberalismo político ha sido la causa popular, movilizadora de los excluidos, en nombre de la soberanía popular y de los derechos. La relación entre el pueblo soberano y el Rule of Law no es, por tanto, problemática. Al contrario, la protección igual bajo el Derecho es una condición fundamental del poder del pueblo, no un obstáculo al mismo $^{93}$. Más allá de los numerosos problemas que debe afrontar el populismo al determinar quién es ese pueblo cuya autoridad se reclama. Porque cualquier particular pueblo soberano es al mismo tiempo una entidad colectiva continuada y un grupo de ciudadanos diferentes que viven y votan en un tiempo determinado. ¿Existe tal entidad o pertenece más bien al reino de las ficciones? El pueblo es una entidad elusiva, diferente del voto mayoritario en un momento dado. No es algo dado sino construido, movilizado y representado, que sólo es agente colectivo a través de reglas y procedimientos constitucionales ${ }^{94}$.

Hasta aquí el elemento común de los análisis parece poner el acento en que el populismo señala los problemas del concepto de representación política, característico de las democracias liberales contemporáneas. No parece que el populismo aporte solución al problema y sí en cambio pondría en riesgo otro elemento clave: la protección de los derechos y libertades individuales. Pero, al menos, pocos dudan que los movimientos populistas pongan de manifiesto las aporías del principio de representación. En otro lugar me he detenido más despacio en esta cuestión, que ahora menciono de manera abreviada ${ }^{95}$. A mi juicio, al menos en un nivel teórico la crisis de la representación política aparece casi con el mismo concepto. Son conocidos los juicios negativos que formula Rousseau sobre la representación política, fuertemente contrapuesta precisamente a la idea de soberanía política ${ }^{96}$. Sin embargo, pocas décadas después, Constant, aun aceptando que el principio de representación es la negación de la soberanía ${ }^{97}$, afirma que esto es solamente el indicio del cambio de nuestro concepto de libertad, asunto que da título a su célebre conferencia ${ }^{98}$. Ahora la libertad es el disfrute de la vida privada, lo que requiere que otros defiendan nuestros intereses

93 CANOVAN, M. (2005), ob. cit., pp. 84-88.

94 Ibidem, p. 85 y p. 89.

95 Las ironías de la sociedad liberal, México, Instituto de Investigaciones Jurídicas de la Universidad Nacional Autónoma de México, 2004, pp. 35-67.

96 ROUSSEAU, J. J. (1762). Du Contract Social en Oeurres Complètes III, B. Gagnebin \& M. Raymond (eds.), Paris, Gallimard, 1964. Se emplea la traducción castellana (que añade un estudio preliminar) de M. J. Villaverde (1988), El contrato social o Principios de Derecho político, Madrid, Tecnos, pp. 94-96.

97 CONSTANT, B. (1819). De la liberté des anciens comparée à celle des modernes. Empleo la traducción castellana (que contiene estudio preliminar y notas) de M. L. Sánchez Mejía (1989), «De la libertad de los antiguos comparada con la de los modernos» (Conferencia pronunciada en el Ateneo de París, Febrero de 1819) en Escritos Políticos, Madrid, Centro de Estudios Constitucionales, p. 261.

98 Ibidem, p. 268. 
públicos, que parecieran ser menos importantes que los privados ${ }^{99}$. A partir de él, no hay en la tradición liberal ninguna referencia negativa al principio de representación de modo que es un lugar común asumido la necesidad de sacrificar una parte de la libertad para conservar otra. Ahora bien, si para esa misma tradición liberal la libertad es solamente la independencia del sujeto, la autonomía del individuo humano ${ }^{100}$, queda sin explicar por qué es más importante nuestra autodeterminación en lo privado que en lo público. Es decir, no sabemos por qué unas libertades gozan de una relevancia mayor hasta el extremo de tener que sacrificar las demás.

Por eso, quiero traer a colación el que a mi juicio es el análisis más profundo y certero que he encontrado y que fue formulado hace ya más de veinte años ${ }^{101}$. Paul Piccone parte de que el populismo estadounidense es la forma histórica particular asumida por la duradera tradición de democracia directa, localismo y especificidad cultural que se remonta mucho más allá de finales del siglo xIX. Incorpora el legado colonial y continúa la tradición norteamericana de comunidades autónomas y autogobernadas ${ }^{102}$. El populismo aparece como problema para los teóricos de la democracia liberal porque éstos consideran al pueblo como fuente última de la soberanía y también de irracionalidad, por lo que requiere de una élite ilustrada que capte la «sensibilidad colectiva» y refrene los «particularismos irracionales» (donde lo entrecomillado viene definido por esa misma élite). En los Estados Unidos la izquierda combatió de este modo el populismo a través de la implantación de un Estado terapéutico, y la derecha lo hizo defendiendo las relaciones predominantes de poder. En ambos casos se sustituyen prácticas de vida multifacéticas por representaciones conceptuales unilaterales sin precisión axiológica lo que abre la vía al nihilismo. Este engaño es consecuencia de la dialéctica de la Ilustración que tan bien habrían descrito Adorno y Horkheimer ${ }^{103}$. Los demócratas estadounidenses no aceptan que desde el New Deal tratan de homogeneizar y hacer pasivos a los ciudadanos con el consiguiente estancamiento que eso genera. Y los republicanos no proponen cómo salir del Estado benefactor a otra solución posible a los problemas que éste resuelve y dejan todo el poder en manos de los actores económicos más fuertes ${ }^{104}$.

99 Ibidem, p. 281.

100 Por ejemplo, puede verse LOCKE, J. (1689). The Second Treatise of Civil Goverment, VI, 57, Cambridge, Cambridge University Press, 1988. También en otros lugares de la misma obra como VI, 63; IV, 22; II, 6, etc.

101 PICCONE, P. (1995). «Postmodern Populism», Telos vol. 103, pp. 81-142. Empleo la traducción castellana de Horacio Pons (1996), «Populismo posmoderno» en ADLER, F. ET ALII (1996), Populismo posmoderno, Bernal (Bs. As.), Universidad Nacional de Quilmes.

102 Ibidem, pp. 81-82 y la bibliografía citada por él.

103 Ibidem, pp. 83-85. En el mismo sentido, hay quien ha incidido en que el reto de la sociedad actual, que hace patente el populismo, es la dificultad de vivir una vez que las sospechas acerca de la dialéctica de la razón ilustrada se han confirmado: VILLACAÑAS, J. L. (2016). Populismo, Murcia, La Huerta Grande, p. 16.

104 Ibidem, pp. 90-92. 
De esta forma, se produce la marginación sistemática de la ciudadanía como resultado de la globalización, la centralización y la despolitización de regímenes liberales burocráticos y centralistas. La crisis de la democracia liberal es una crisis motivacional y de racionalidad, porque al depender cada vez más de la intervención estatal y de la ingeniería social, no queda espacio entre la burocracia y los ciudadanos cuyas relaciones no son intersubjetivas sino asimétricas. La racionalidad burocrática produce separación y aislamiento y aumenta la relación de dependencia donde uno es sujeto dador y activo y el otro es objeto receptor y pasivo. El populismo posmoderno resurge de la frustración que genera el déficit democrático, la ineficiencia y la inadecuación. Pero al ser un movimiento reactivo le falta capacidad de articular ideas teóricas y corre el riesgo de ser reconfigurado en el sistema presente a expensas de la participación y la autonomía ciudadana ${ }^{105}$.

\subsection{El populismo y el sentido contemporáneo de lo político}

Llegados a este punto del análisis, cabe preguntarse si es posible ir todavía más al fondo de la cuestión. Hasta aquí pareciera que las dificultades de nuestras democracias presentes que ponen de relieve los populismos tienen que ver con la propia dinámica de una sociedad de masas y las limitaciones consiguientes del principio de representación. Pero el último de los análisis expuestos pone el acento en una insatisfacción y extrañamiento más hondos que parece ser el motor de quienes promueven y apoyan los movimientos populistas. Y frente al populismo pareciera que la única reacción posible desde los planteamientos liberales es mostrar los riesgos y peligros de aquel, sin terminar de tomar en serio los desafíos y las críticas.

Hay, a mi juicio, un aspecto del populismo que ha sido señalado por algunos autores y que es señal de que cabe un análisis más profundo. En los últimos años, el populismo se manifiesta en un lugar como Francia que ha sido caracterizado como la menos liberal de las democracias. Y ha aparecido en los Estados Unidos de América, que poseen una robusta sociedad civil, donde la participación ciudadana en lo público es mayor y no es tan grande la distancia entre representantes y representados. $\mathrm{O}$ dicho de otro modo, hay que preguntarse por qué aparece el populismo en democracias maduras con gobiernos legitimados por mayorías populares y donde la élite política es más amplia que en tiempos pasados ${ }^{106}$.

A mi modo de ver, hay que partir de que el planteamiento moderno del sentido y origen de la comunidad política es ajeno al imaginario anterior ${ }^{107}$. Y es que para

105 Ibidem, pp. 131-132.

106 CANOVAN, M. (2005), ob. cit., pp. 80-82.

107 En los párrafos que siguen soy deudor de la inspiración de la lectura de CRUZ PRADOS, A. (2009). Filosofía Política, Pamplona, Eunsa. He desarrollado las ideas expuestas con más detalle en (2017) «La noción de Soberanía en la encrucijada de sentido del Derecho y la Política», Anuario Filosófico 50 (en prensa). 
tratar de comprender lo político, el pensamiento moderno necesita pensar en una realidad previa a la politicidad en la que ésta se da. Esta realidad puede ser individual o colectiva. Es fácil advertir que en las primigenias teorías del contrato social esa realidad previa es el individuo singular. Lo que modifican las ideologías totalitarias o no liberales modernas es el quién de esa realidad previa: ahora es una colectividad. Pero, en todo caso, lo político es un momento posterior. Se inaugura así un modo binario de pensar que opone el sujeto (individual o colectivo) a la propia politicidad del mismo ${ }^{108}$.

Como puede observarse, el pensar binariamente es también el producto de considerar que la comunidad política aparece como una creación de las voluntades de quienes pactan. Pero ha sido creada precisamente como lo otro, porque de un modo $\mathrm{u}$ otro nos hemos despojado de algunos de nuestros bienes o al menos porque aparece como el producto de una cesión del uso irrestricto de nuestra voluntad. En efecto, de la regla general de razón que ordena que cada hombre en el estado de naturaleza debe esforzarse por la paz, se sigue «que uno acceda, si los demás consienten también, y mientras se considera necesario para la paz y defensa de sí mismo, a renunciar a este derecho a todas las cosas y a satisfacerse con la misma libertad» ${ }^{109}$. Y en ese mismo capítulo, Hobbes insiste en hablar varias veces más de renuncia, abandono o transferencia del derecho. Si precisamente en nuestro imaginario contemporáneo nos comprendemos como pura autonomía, es difícil reconocerse en aquello que es producto de la pérdida de lo que nos constituye como humanos: la autonomía de nuestra voluntad. La comunidad política es solamente el producto de nuestra voluntad, pero no sólo de la mía o no completamente. No pudiendo entonces reconocernos en ella, la comunidad política adquiere entonces caracteres de sujeto diferente y distinto al propio yo. Es decir, la polis (ahora Estado) se ha hipostasiado, y con ello se ha convertido en un peligro. Tal vez responda a que su ausencia supone un peligro mayor, pero en todo caso es un peligro. Caben entonces dos opciones. O ser instrumentalizado por ella o tratar de instrumentalizarla. Pero, más allá de las luchas ideológicas pasadas, lo que permanece inamovible es la misma comprensión hipostasiada de la comunidad política. Si esta es nada más que la creación de un acto de voluntad (o de una suma de voluntades), puede entenderse que aparezca también con voluntad propia. Y entonces está servido el conflicto de voluntades.

Y es que como toda realidad compuesta de seres vivos, el Estado pareciera tener también vida propia. Al pensarse a sí mismo como una realidad previa, el individuo singular tiene la consideración de lo otro (en este caso el Estado) como peligro, o incluso enemigo, por el simple motivo de que no parece posible reconocerse en él sino sólo en mí mismo. Para la mentalidad moderna que tiene por centro el valor de la autonomía de la voluntad, la propia realidad, la propia identidad, donde uno se reco-

108 En el momento presente de la historia, parece haber triunfado el ideal de las primitivas teorías políticas de la modernidad: tal realidad previa es el sujeto humano individual y singular.

109 HOBBES, T. (1651). Leviathan I, 14. Se emplea la traducción castellana de Manuel Sánchez Sarto (1996), México D.F., Fondo de Cultura Económica. 
noce, es apenas en sí mismo y con dificultad en algunos de sus semejantes. De modo que si tengo dificultad para reconocerme en el otro, mucho menos voy a reconocerme en una realidad posterior que viene a pretender ser la suma de todos. Esa realidad otra, que llamamos comunidad política y que adopta ahora los caracteres del Estado, es si cabe peor porque es más grande y más fuerte que uno. Y está, eso sí, tan viva como uno, porque está formada por seres humanos. Así, ese otro es una realidad viva, que opera con mayor fuerza que un ser humano y que carece precisamente de aquello que puede hacer que uno se reconozca en él. Por eso, el afán cada vez mayor del ser humano ha sido no sólo evitar ser dominado por el Estado, sino también tratar de dominarlo a él para emplear precisamente toda su fuerza.

La comunidad política en forma de Estado se presenta entonces como una estructura artificial que consiste fundamentalmente en poder. $Y$ un poder que entra en inevitable conflicto con la realidad previa que, como mencionamos, es el individuo y sus derechos. Porque la verdad sobre el ser humano sólo se encontraría en ese conjunto de derechos previos a la politicidad, precedentes incluso a su dimensión comunitaria. Lo político es algo a lo que nos vemos abocados a regañadientes y en este repliegue del individuo sobre sí mismo, lo comunitario se ve siempre como peligroso, no identitario, ajeno. No es que se haya alejado del sujeto singular sino que estaba lejos desde el principio. El impulso lleva a alejarse de esa construcción peligrosa donde uno no puede reconocerse porque no sirve a sino que más bien conspira contra el propio proyecto vital.

Desde la perspectiva recién descrita, carece de sentido pretender que exista un bien común político. El bien es siempre particular. Lo más parecido a un bien común es la maximización de los bienes particulares coincidentes. Pero esos bienes no son propiamente comunes sino singulares y coincidentes, es decir, tenemos por bienes particulares realidades similares, o apreciamos como buenos los mismos bienes particulares. Pero el carácter de bondad de una realidad es siempre individual, singular, particular. El sentido de nuestras comunidades políticas es la protección de los bienes particulares y nada más. Esto último se pone también de manifiesto en el modo de darse el pacto social. Este pacto sólo se realizará por interés, como se deduce cuando Hobbes afirma que «cuando alguien transfiere su derecho, o renuncia a él, lo hace en consideración a cierto derecho que recíprocamente le ha sido transferido, o por algún otro bien que de ello espera, porque se trata, en efecto, de un acto voluntario, y el objeto de los actos voluntarios de cualquier hombre es algún bien para sí mismo» ${ }^{110}$. Dicho pacto no significa, por tanto, que se asuma un proyecto común, o el reconocimiento de un bien superior que se alcanza mediante la estrecha colaboración de todos. De ahí, que el contenido del pacto no sea una idea común de lo que constituye una vida buena, sino más bien el interés de cada uno por su conservación ${ }^{111}$. El ciudadano acepta el pacto para favo-

$\begin{array}{ll}110 & \text { Ibidem. } \\ 111 & \text { SPAEMANN, R. (1980). Crítica de las Utopías Políticas, Pamplona, Eunsa, p. } 202 .\end{array}$ 
recer su conservación y puede desecharlo por el mismo fin. Como consecuencia de lo anterior, puede concluirse que la conclusión del pacto o contrato está, en Hobbes, guiada internamente por la idea de la propia conservación ${ }^{112}$.

Y así, desde Hobbes el fin de la sociedad es puramente instrumental. La pertenencia del hombre a la sociedad no tiene una finalidad relacionada con el perfeccionamiento o bien propio del hombre, sino un sentido de mera supervivencia. Lo que está detrás latiendo no es sino una comprensión del hombre que en el fondo resulta vacía. Del mismo modo que la libertad del hombre era, en un primer momento, omnímoda y en último término carecía de fines propios; paralelamente, el hombre que se reúne en sociedad sigue careciendo de fines más allá de su permanencia en el ser. En nuestra opinión, la pérdida de la noción de finalidad a la hora de hablar del hombre y de su libertad conlleva un empobrecimiento en el momento de concebir el hecho social porque éste en último término también es un hecho humano. En la sociedad tal y como se la concibe desde Hobbes el hombre no puede reconocerse, sólo puede sobrevivir. La ley posee una justificación funcional exclusivamente por referencia a la supervivencia humana. Pero no parece uno de los elementos básicos para el correcto desarrollo de la vida humana. Por tanto, como ya se dijo, lo positivo del hombre vendría a ser todo aquello que pudiera desarrollarse al margen de ella. En este sentido se entiende el carácter meramente instrumental de la comunidad política para la mentalidad moderna. La comunidad política, ahora el Estado, no añade nada al individuo singular en cuanto a sus fines: se pretende que no sea más que un simple medio eficiente. Pero, al mismo tiempo, se trata de un medio con vida propia y que es capaz de invertir la relación, es decir, de convertir al individuo en medio para sus fines. Por lo anterior, se entiende que dicho conflicto no tenga otra solución que no sea la victoria de una voluntad (la del individuo o la de la comunidad) sobre la otra.

Lo anterior explica también que el contenido del pensamiento político a partir de la modernidad ha sido precisamente el poder. Porque ahora en el origen de lo político no hay sino un acto de voluntad, y a lo que da lugar es a una comunidad que se caracteriza precisamente por la soberanía. Es decir, por una voluntad que detenta la supremacía, es decir, que se impone. De esta manera, se reduce la participación en lo político a ejercer de alguna forma un acto de poder. El objeto de la reflexión política parece reducirse a la conquista, preservación y ejercicio del poder, al diseño de sus límites y cómo superar esos límites. Esto último no sólo ocurre si se piensa en los partidos políticos o en los representantes como sujeto de todas esas operaciones (conquista, ejercicio, preservación, etc.). También si se piensa en el individuo concreto como sujeto frente a sus propios representantes (o frente a los partidos políticos que intermedian entre ambos): en este caso, los contrapesos al poder, la división de poderes, los derechos individuales, etc., son también vistos

112 KAVKA, G. S. (1986). Hobbesian Moral and Political Theory, Princeton, Princeton University Press, 179 y ss. 
como conquista, ejercicio y preservación del poder. En último término, si no hay más que un conflicto más o menos complejo de voluntades, se comprende que no se hable más que de poder. Todo lo cual muestra la imposibilidad de pensar en términos de verdadera comunidad porque no hay bienes que compartir. El poder, por su propia naturaleza, refleja el alcance de cada voluntad y en este sentido toda voluntad ajena es límite de la propia. Cuando los demás son límites es porque constituyen de nuevo una realidad distinta, ajena a mí, con quien sólo puede haber en el mejor de los casos coincidencia o compatibilidad, pero difícilmente habrá verdadera comunidad.

\section{Conclusiones}

Todo lo anterior nos aproxima a la comprensión del fenómeno populista. En efecto, en primer lugar, está la cuestión de qué esperamos del gobernante. Si en el fondo estamos ante un problema de poder, de su conquista y preservación, en realidad permanecemos en el ámbito de los juegos de voluntades. Y la pregunta que se hace quien gobierna sigue firme: ¿por qué debo aceptar límites a mi voluntad? En el fondo no se aceptan sino que se imponen. El por qué existen frenos al ejercicio del poder es algo que no termina de explicarse. O, mejor dicho, algo para lo cual se da una razón o justificación extra política. Pero, vistas las cosas con perspectiva netamente política, lo único que debe hacer quien gobierna es imponer su voluntad. A fin de cuentas, es la pasión por imponer la propia voluntad lo que le ha llevado hasta allí y lo que le sostiene en su afán por permanecer. No debe extrañarnos entonces que emplee todos los métodos a su alcance para lograr su propósito porque todos son políticos en la medida en que son ejercicio del poder. En último término, las razones extra políticas que se plasman en el Derecho para limitar tal ejercicio de poder pueden seguir siendo vistas como otras voluntades que aspiran al poder en pugna con quien lo detenta. Seguiríamos así en el irresoluble conflicto de voluntades, en la medida en que no hay nada realmente al margen de éstas. La desconfianza hacia lo político de quienes no ejercen el poder es inevitable en este orden de cosas. Y parece inevitable la tendencia de quienes lo ejercen por sobrepasar las barreras extra políticas que se les ponen.

Esto explicaría también que nos resulte intolerable que la acción de quien ejerce el poder suponga de algún modo una pérdida de nuestras libertades privadas que consisten principalmente en nuestra autonomía económica. Por eso, lo peor que puede hacer quien gobierna es subir los impuestos, enriquecerse a costa del erario público, no lograr modificar el curso de la actividad económica cuando ésta genera desempleo o inflación, etc. En el fondo, lo que buscamos en nuestros representantes es un gestor (por acción o por omisión) de lo económico y nada más. De ahí, que los límites que le ponemos al poder político sean los recién descritos. Lo que ocurra en el ejercicio de éste no nos importa mientras nos permita el máximo ejercicio de nuestra autonomía en lo privado. Por eso, hoy en día hablar de Política es cada vez 
más hablar de Economía. De la misma manera, se explica la actual profesionalización de lo político. Se trata de un problema de gestión, palabra característica del mundo empresarial. Pero estamos ante una realidad meramente técnica. Se requieren gestores económicos que sean capaces de permitirme maximizar en la medida de lo posible mis libertades económicas privadas.

Por lo dicho hasta ahora se entiende que la situación descrita genera la desafección de la vida política por parte de los ciudadanos. Principalmente porque tomar parte en lo político es participar en algo ajeno, en lo otro. ¿Para qué voy a querer participar en algo que me resulta ajeno? No tiene sentido entrar en un ámbito donde no es posible encontrar la propia identidad. Es más, lo lógico es buscar a alguien que me represente. De este modo puedo dedicarme a ejercer el conjunto de libertades de la vida privada, donde me encuentro y me identifico, y entregar a otros los ámbitos de mi desinterés. No se trata de que ésta sea la causa de la aparición del principio de representación política, pero concuerda perfectamente con el sentido que se le da en el Estado moderno. De nuevo, podemos observar que las tensiones entre representante y representado tienen difícil solución si el contenido de lo político es únicamente el poder. Buscamos a alguien que nos represente pero damos por hecho que propiamente está ahí no tanto para eso cuanto para permanecer en el poder y ejercerlo. Y, entonces, más pronto o más tarde descubrimos de nuevo que lo político nos afecta fuertemente, pero para entonces está fuera de nuestro control porque en gran medida siempre lo ha estado. Ese descubrimiento genera los fenómenos populistas frente a los cuales las respuestas de nuestra propia visión moderna de lo político serán siempre insatisfactorias. No es solamente un problema generado por el tamaño de nuestras comunidades políticas, por su carácter cada vez más anónimo, centralizado y complejo. Es cierto que se hace necesaria una recuperación y fortalecimiento de las instituciones sociales y políticas que posibilitan la participación. Pero para que tal cosa sea real hace falta antes que lo político sea un ámbito realmente propio.

\section{Title}

Populism and modern meaning of Politics

\section{Summary:}

1. The concept of populism. 1.1 An historical approach. 1.2. Some attempts of characterization. 1.3. The remains of the concept of populism. 2. Populism, democracy and liberalism. 2.1. Status quaestionis. 2.2. Populism and modern meaning of Politics. 3. Conclusion. 


\title{
Resumen:
}

Nadie duda que los actuales fenómenos populistas han generado esperanza en unos y preocupación en otros. Incluso entre quienes genera esperanza parece necesario tomarse en serio la preocupación ajena. En este punto, el populismo actual supone negar un estado de cosas que parecía inconmovible. De ahí que valga la pena hacer un esfuerzo por comprenderlo.

En este sentido, el propósito de este trabajo es doble. En primer lugar, vamos a afrontar el problema de la conceptualización del populismo. Para eso se sigue un doble acceso. Por un lado, se pretende mostrar la heterogeneidad de los populismos mediante una aproximación, a través de los estudios más canónicos, a sus principales manifestaciones históricas. Por otro lado, dicha heterogeneidad se manifiesta también en los intentos de caracterizarlo. A este respecto, la literatura académica es tan abundante y los rasgos que se le han dado son tan numerosos, que nos centraremos en algunos elementos fundamentales. En concreto, la cuestión de sus causas, su condición de fenómeno reactivo (o anti), la figura central del líder carismático populista y la comprensión del pueblo que subyace. Con esta doble vía de acceso al problema se pretende mostrar que el debate ha llegado a un callejón sin salida y se propone una manera operativa de evitarlo.

Las dificultades de su conceptualización dan la medida del segundo propósito de estas líneas. Y es que como parece inasible, se hace más perentorio comprender bien cómo el populismo presente desafía las democracias liberales contemporáneas. Este reto ha sido analizado de nuevo de manera abundante. Tras mostrar algunos ejemplos de los distintos niveles de análisis posibles, se presenta uno propio que intenta llegar al fondo de la cuestión: el populismo es ante todo un síntoma de las dificultades de nuestra comprensión de lo político, de esa que forma parte de nuestro imaginario y que hunde sus raíces en el pensamiento moderno.

\begin{abstract}
:
Nobody doubts that present populism has spurred sentiments of hope and concern. Even among those who react hopefully, it seems necessary to take others' concern seriously. In effect, present populism shakes a state of affairs that once seemed unmodifiable. It is therefore worth trying to understand it.

In this context, this work aims at a double purpose. In the first place, we will afford the problem of conceptualizing populism, through a two-fold strategy. On the one hand, we will approach the main historical instantiations of populism, in view of displaying its heterogeneous nature. On the other hand, this heterogeneity reveals itself in a variety of intents of conceptualization, which explains the convenience of focusing our own conceptualization on only some of its main features: its causes, its reactive nature, the charismatic leader, and the people underlying it. This two-fold strategy will allow us to prove that discussions concerning populism have reached a dead end, and we propose a way of surpassing it.
\end{abstract}


The second purpose of this study is to understand the way in which populism threatens present liberal democracies. After discussing some of the available levels of analysis, we present an alternative methodology, intending to reach the core of the problem: populism is, above all, a sign of the problems of our own understanding of the realm of politics, that which is a part of our imaginary and takes root in modern thought.

Palabras clave:

Populismo. Política. Democracia.

Keywords:

Populism. Politics. Democracy. 